\title{
Program P2M Penerapan Ipteks : Pelatihan Pembuatan Serta Pemanfaatan Blog Akademis Dengan Akses Mobile Bagi Guru-Guru di SMK Negeri 1 Klungkung
}

\author{
Agus Aan Jiwa Permana ${ }^{1)}$, A.A. Gede Yudhi Paramartha ${ }^{2)}$, Komang Setemen ${ }^{3)}$ \\ Prodi Manajemen Informatika, Universitas Pendidikan Ganesha, Singaraja, Bali 1) 2) 3) \\ agus.aan@undiksha.ac.id
}

\begin{abstract}
According to the Law of the Republic of Indonesia Number 14 Year 2005 on Teachers and Lecturers, Teachers are professional educators with the primary task of educating, teaching, guiding, directing, train, assess, and evaluate students on early childhood education formal, basic education and secondary education, Spreading knowledge is one of the functions of teachers as a teaching service provider to be received by the learners. Internet technology can be used as a means of discussion, exchange ideas and interaction between teachers and learners. Therefore we need a means of interaction on the Internet that can be used for such purposes. One of the technologies used for the above purpose is Blog. Blog is a technology used for Internet-based online publication that is fairly easy to operate. Users can write any blog freely and can be seen by everyone via the internet.Readers of a blog page can post comments on the article, so that blogs can also be used for means of discussion. One further development of the blog is the application of mobile technology, where the resources available on the Internet can be accessed from a smartphone or tablet that can easily be carried anywhere.
\end{abstract}

Keywords : Teachers and Lecturers, education, blog, article, online publication

\begin{abstract}
ABSTRAK
Menurut Undang-Undang Republik Indonesia Nomor 14 Tahun 2005 tentang Guru dan Dosen, Guru adalah pendidik profesional dengan tugas utama mendidik, mengajar, membimbing, mengarahkan, melatih, menilai, dan mengevaluasi peserta didik pada pendidikan usia dini jalur formal, pendidikan dasar dan pendidikan menengah. Menyebarkan ilmu pengetahuan merupakan salah satu fungsi guru sebagai penyedia layanan pengajaran yang akan diterima oleh para peserta didik. Teknologi internet dapat digunakan sebagai sarana diskusi, bertukar pikiran dan interaksi antara guru dan peserta didiknya. Maka dari itu diperlukan suatu sarana interaksi di internet yang dapat digunakan untuk tujuan tersebut. Salah satu teknologi yang digunakan untuk tujuan di atas adalah Blog. Blog merupakan suatu teknologi yang digunakan untuk publikasi online berbasis internet yang cukup mudah untuk dioperasikan. Pengguna blog dapat menulis apapun secara bebas dan dapat dilihat oleh semua orang melalui internet. Pembaca suatu halaman blog dapat memposting komentar tentang tulisan tersebut, sehingga blog dapat juga digunakan untuk sarana diskusi. Salah satu perkembangan lanjut dari blog adalah penerapan teknologi mobile, dimana sumberdaya yang ada di internet dapat diakses dari smartphone atau tablet yang dapat dibawa dengan mudah ke mana saja.
\end{abstract}

Kata Kunci : Guru dan Dosen, Pendidikan, Blog, Artikel, Publikasi Online 


\section{PENDAHULUAN}

Menurut Undang-Undang Republik Indonesia Nomor 14 Tahun 2005 tentang Guru dan Dosen, Guru adalah pendidik profesional dengan tugas utama mendidik, mengajar, membimbing, mengarahkan, melatih, menilai, dan mengevaluasi peserta didik pada pendidikan usia dini jalur formal, pendidikan dasar dan pendidikan menengah. Menyebarkan ilmu pengetahuan merupakan salah satu fungsi guru sebagai penyedia layanan pengajaran yang akan diterima oleh para peserta didik. Guru dalam mendidik tidak hanya melakukan kegiatan belajar mengajar di kelas, namun dapat dilakukan dalam kegiatan di luar kelas seperti dengan memanfaatkan teknologi informasi sebagai sarana belajar mengajar.

Antara guru dengan siswa seharusnya terjalin komunikasi yang baik bukan saja di dalam, namun juga di luar sekolah. Terbatasnya komunikasi serta faktor minimnya media akses pengetahuan di lingkungan sekolah, dapat disebabkan karena kesibukan guru atau mungkin siswa karena mengikuti kegiatan-kegiatan tertentu di sekolah seperti OSIS yang jadwalnya padat. Kegiatan transfer pengetahuan sebenarnya dapat dilakukan di luar kelas, sebagai antisipasi sehingga tidak dapat selalu bertemu dengan guru yang bersangkutan. Dalam hal lain, teknologi internet yang berkembang pesat saat ini dapat dimanfaatkan sebagai sarana dalam menyebarkan ilmu pengetahuan bagi guru. Bahan ajar berupa materi dapat diunggah ke internet sehingga para peserta didik dapat mengambil materi-materi tersebut sebagai bahan belajar. Teknologi internet dapat digunakan sebagai sarana diskusi, bertukar pikiran dan interaksi antara guru dan peserta didiknya. Maka dari itu diperlukan suatu sarana interaksi di internet yang dapat digunakan untuk tujuan tersebut.

Salah satu teknologi yang digunakan untuk tujuan di atas adalah Blog. Blog merupakan suatu teknologi yang digunakan untuk publikasi online berbasis internet yang cukup mudah untuk dioperasikan. Pengguna blog dapat menulis apapun secara bebas dan dapat dilihat oleh semua orang melalui internet. Pembaca suatu halaman blog dapat memposting komentar tentang tulisan tersebut, sehingga blog dapat juga digunakan untuk sarana diskusi. Salah satu perkembangan lanjut dari blog adalah penerapan teknologi mobile, dimana sumberdaya yang ada di internet dapat diakses dari smartphone atau tablet yang dapat dibawa dengan mudah ke mana saja. Blog yang menggunakan teknologi mobile disebut dengan mobile blogging, dimana pengguna blog dapat menulis suatu halaman blog menggunakan smartphone atau tablet yang dimilikinya. Akses blog menggunakan mobile prosesentasenya mencapai $17.8 \%$ (lihat Gambar 1)

Dengan adanya teknologi blog dengan akses mobile diharapkan dapat menjawab permasalahan guru untuk dapat menyebarluaskan ilmu pengetahuan yang dimilikinya. Bahkan teknologi internet dan penggunaan smartphone sudah banyak digunakan di kalangan guru khususnya guru-guru di perkotaan. Meskipun demikian, tidak semua guru memiliki pengetahuan untuk memanfaatkan teknologi tersebut. Sehingga, kegiatan pengabdian kepada masyarakat ini diusulkan untuk melatih guru dalam membuat suatu blog akademis dan memanfaatkannya untuk menyebarkan ilmu pengetahuan yang dimilikinya. Selain itu, pelatihan pemanfaatan teknologi mobile blogging juga akan dilakukan agar guru dapat melakukan posting ke blog atau sekedar mengecek kometarkomentar pada postingan dari para siswanya dengan menggunakan teknologi mobile.

Guru sebagai tenaga pendidik berkewajiban mendidik, mengajar, membimbing, mengarahkan, melatih, menilai, dan mengevaluasi peserta didik dalam hal ini adalah siswa. Waktu dan tempat sering menjadi kendala dalam menjalankan kewajiban tersebut. Guru masih awam dalam memanfaat sarana akademis untuk digunakan menyebarkan ilmu pengetahuan yang dimilikinya, menuangkan ide dalam sebuah tulisan akademis, atau untuk berbagi materi ajar untuk para peserta didik baik di sekolah maupun di luar sekolah. Hal ini juga dapat membantu para guru untuk mengembangkan kemampuannya menulis.

Informasi telah berkembangan dengan sangat pesat karena internet sudah dapat diakses dengan sangat mudah (paling tidak di perkotaan), sehingga teknologi internet seharusnya dapat digunakan untuk membantu pembelajaran. Penggunaan smartphone dan tablet juga telah digunakan secara luas oleh guru maupun peserta didik, sehingga teknologi ini dapat dimanfaatkan untuk keperluan akademis. Begitu juga dengan teknologi blog dan mobile blogging banyak tersedia secara bebas di internet, sehingga guru tidak harus melakukan instalasi secara mandiri atau membayar untuk memanfaatkannya. 
Dengan adanya teknologi-teknologi di atas selayaknya dapat membantu menyelesaikan kendala yang dimiliki oleh guru dalam menyebarluaskan pengetahuan yang dimilikinya. Untuk itu pada usulan pengabdian kepada masyarakat ini diusulkan untuk melakukan kegiatan pelatihan pembuatan dan pemanfaatan blog dan mobile blogging kepada guru untuk keperluan akademis. Kegiatan ini akan dilangsungkan di SMK Negeri 1 Klungkung. Diharapkan dengan adanya kegiatan ini dapat mempermudah guru dalam menyebarkan ilmu pengetahuan yang dimilikinya kepada peserta didik maupun masyarakat luas.

\section{TINJAUAN PUSTAKA}

Adapun beberapa pelatihan blog yang diselenggarakan sebelumnya dalam rangkaian pengabdian pada masyarakat di UNDIKSHA seperti Pelatihan Pembuatan Blog Sebagai Media Bisnis Internet Di Era Globalisasi Bagi Mahasiswa D3 Undiksha Singaraja (I Nyoman Putu Suwindra, . 2008), Pelatihan Pemanfaatan Blog bagi Guru-Guru SMA Se-Kecamatan Seririt Dalam Upaya Meningkatakan Motivasi Belajar Siswa (Komang Setemen, 2010), Pelatihan Pembuatan Blog Sebagai Media Promosi dan Bisnis Internet di Era Global Bagi Guru-Guru SMP Di Kecamatan Buleleng (I Gede Mahendra Darmawiguna, 2013). Penerapan dan Pelatihan Pengoperasian Blog Akademis Bagi Dosen Undiksha (I Ketut Resika Arthana, 2015). Berdasarkan hal tersebut, maka perlu diadakan pelatihan berkelanjutan terhadap guru-guru di sekolah lain, misalnya saja di SMK Negeri 1 Klungkung. Adapun keunggulan dari program ini adalah pengembangan akses mobile blogging yang dapat mempermudah memanajemen dan mengakses halaman blog yang belum pernah dilakukan pada kegiatan sebelumnya. Beberapa pustaka terkait dengan penelitian ini adalah.

\section{BLOG}

Web Log atau yang sering juga disebut BLOG adalah sebuah diary atau catatancatatan pribadi yang disimpan secara online dan umumnya bersifat terbuka bagi siapa saja yang ingin membacanya (Ristianto, 2015). bisa juga berisi kutipan dari sumber lain yang sengaja dipublikasikan kembali dalam satu tempat. Blog juga sama dengan situs-situs atau web yang sering Anda temui di internet. Materi dan konten merupakan kebebasan penuh dari sang pembuat blog. tentu saja sangat disarankan lebih ke arah membagi pengetahuan yang bermanfaat. Blog menawarkan beberapa keunggulan (Haines, 2010) :

- Pertama-tama, jika Anda memilih untuk memulai sebuah blog, Anda bisa membuat website yang cukup tampak licin tanpa keterampilan teknologi khusus. Anda bahkan dapat menanamkan gambar dan video Anda sendiri untuk situs en-hance Anda.

- Blog telah built-in fitur interaktif yang AI-rendah pembaca untuk menanggapi melalui komentar untuk Infor-masi diposting di blog.

- Fitur komentar adalah plus besar, mengingat keinginan orang tua untuk dapat berinteraksi dan memberikan umpan balik.

- Akhirnya dan mungkin yang paling penting adalah gratis

\section{WEBSITE}

Betha (2004) menyatakan, web merupakan kumpulan dari halaman-halaman situs yang biasanya terangkum dalam sebuah domain atau subdomain yang tempatnya berada di dalam WWW (World Wide Web) di internet. Sebuah halaman web dokumen yang di tulis dalam format HTML (Hyper Text Markup Language) hampir selalu bisa diakses melalui HTTP. HTTP yaitu protocol yang menyampaikan informasi dari server website untuk ditampilkan kepada para pemakai melalui webbrowser. Semua publikasi dari website-website tersebut dapat membentuk sebuah jaringan informasi yang sangat besar. 


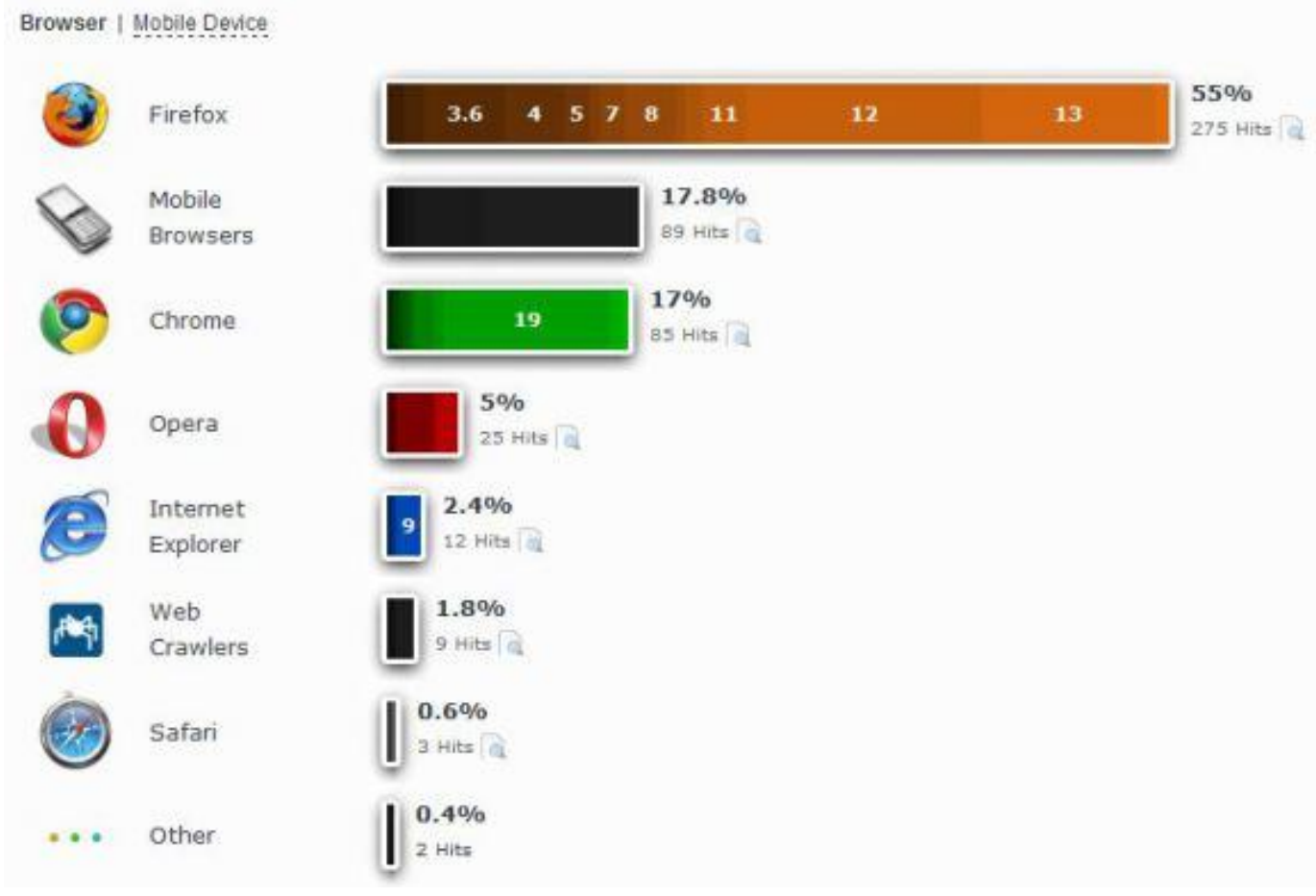

Gambar 1. Data Akses Blog Dengan Mobile

( Sumber : Hasan, 2012 )

WWW diciptakan pertama kali pada tahun 1989 oleh dua orang peneliti bernama Tim Berners Lee dari Inggris dan Robert Cailliau dari Belgia. Keduanya menciptakan $W W W$ ketika bekerja pada proyek Cern di Jenewa, Swiss. Demi kemudahan komunikasi dan penyaluran informasi antar anggota yang tersebar di seluruh dunia, para peneliti CERN menciptakan sebuah sistem distribusi yang bisa menampilkan informasi dalam bentu grafik, gambar, atau suara. Pada awal pembuatannya,Web browser dibuat hanya berbasis teks pada komputer saat itu. Namun, pengguna web browser tersebut perlahanlahan ditinggalkan sejak kedatangan web browser yang bernama Mosaic. Mosaic merupakan hasil dari sebuah penelitian yang lebih baik, karena memudahkan pengguna dalam pengoperasiannya juga sudah berbasis grafik. Kepopuleran Mosaic digantikan Netscape Navigatorciptaan SiliconGraphics. Microsoft juga meramaikan hadirnya web browseryang bernamaInternetExplorer.

Pada tahun 1994, Netscape Navigator merupakan web browser yang banyak digunakan selain InternetExplorer. Sampai sekarang ini banyak web browser yang banyak digunakan adalah Mozilla Firefox, Google Chrome yang dibuat oleh raksasa internet Google.inc, dan Opera buatan OperaSoftwareASA.

Website itu sendiri terbagi menjadi dua jenis yaitu website statisdan website dinamis. Website statis adalah website yang informasi di dalamnya tidak dimaksudkan untuk diperbaharui. Website ini biasanya memiliki seorang atau sebuah tim administrator yang menangani penggunaan software editor. Sedangkan website dinamis adalah website yang informasi di dalamnya diperbaharui secara berkala. Penggunaan website berhubungan dengan pengguna publik yang membutuhkan interaksi dua arah (antara administrator website dengan pengguna).

\section{INTERNET}

Internet (Interconnected Computer Networks) bisa didefinisikan network komputer tiada batas yang menjadi penghubung pengguna komputer dengan pengguna komputer lainnya serta dapat berhubungan dengan komputer di sebuah wilayah ke wilayah di penjuru dunia, di mana di dalam jaringan tersebut mempunyai berbagai macam informasi serta fasilitas layanan internet browsing atau surfing. Internet juga merupakan sistem global jaringan komputer yang berhubungan meng- 
gunakan standar Internet Protocol Suite (TCP/IP) untuk melayani miliaran pengguna

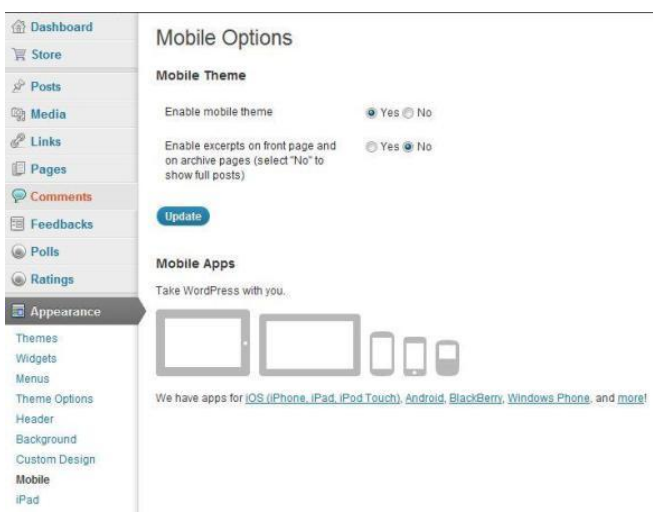

\section{Gambar 2. Fitur Seting Akses Mobile di Wordpress (Sumber : Hasan, 2012 )}

Hal itu merupakan jaringan dari jaringan yang terdiri dari jutaan jaringan pribadi, umum, akademik, bisnis, dan jaringan pemerintah dari lokal ke lingkungan global, yang dihubungkan oleh sebuah kode array yang luas dari teknologi jaringan

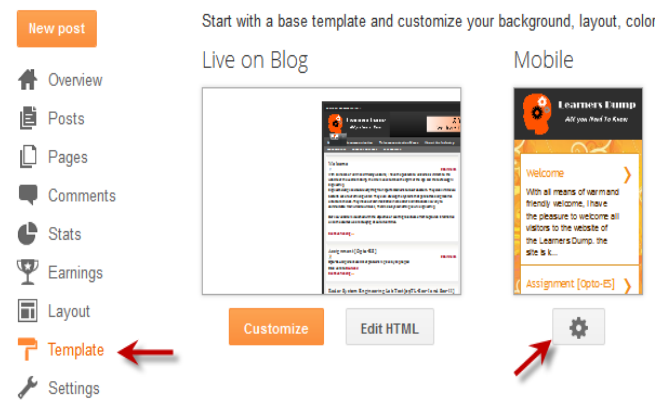

\section{Gambar 3. Fitur Seting Akses Mobile di Blogger (Sumber : Lia, 2014 )}

elektronik, nirkabel, dan optik. Internet juga dapat didefinisikan sebagai interkoneksi seluruh dunia komputer dan jaringan komputer yang memfasilitasi sharing atau pertukaran informasi di antara pengguna (Sutiyadi, 2006).

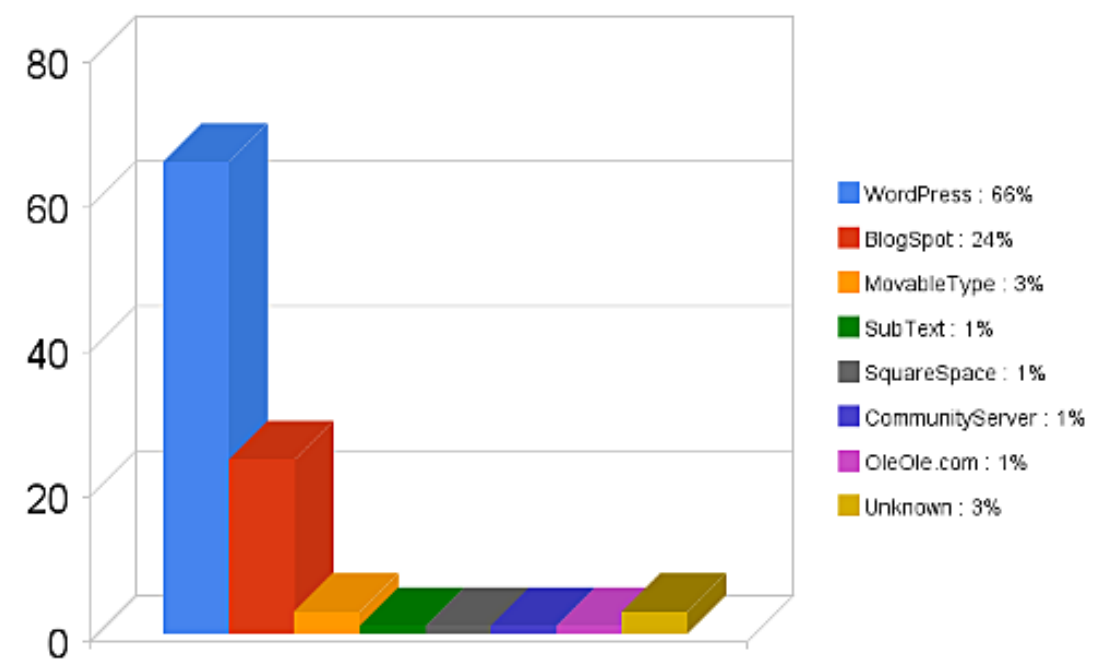

Gambar 4. Perbandingan Penggunaan Wordpress dan Blogger

( Sumber : https://mav3rickcarb1ne.files.wordpress.com/2009/11/pub.png )

\section{MOBILE BLOGGING}

Masyarakat yang makin dinamis dengan didukung kecanggihan teknologi terkini memungkinkan kegiatan blogging bisa dilakukan melalui telepon genggam secara mudah. Aktifitas blogging bukan hanya dido-minasi melalui perangkat personal com-puter (PC) maupun laptop. Kemudahan mengakses internet melalui telepon genggam menjadikan kegiatan blogging semakin menarik, mudah, tidak ribet dan bisa dila- kukan dimana saja (Siswoyo, 2011). Adapun data terkait dengan banyaknya akses melalui mobile dapat dilihat pada Gambar 1. Kabarnya google akan mengeluarkan algoritma terbarunya, yaitu mobilegeddon, yang mengamati bahwa $50 \%$ pencarian google adalah berasal dari mobile atau smartphone, maka seorang blogger bisa lebih mengoptimalkan blognya dengan baik di perangkat mobile(Lie,2014). 


\section{PERMASALAHAN}

a. Masih minimnya sarana sharing ilmu pengetahuan yang dimiliki oleh guru

b. Belum semua guru mampu membuat dan memanfaatkan blog dan mobile blogging maupun mengisi konten blog tersebut

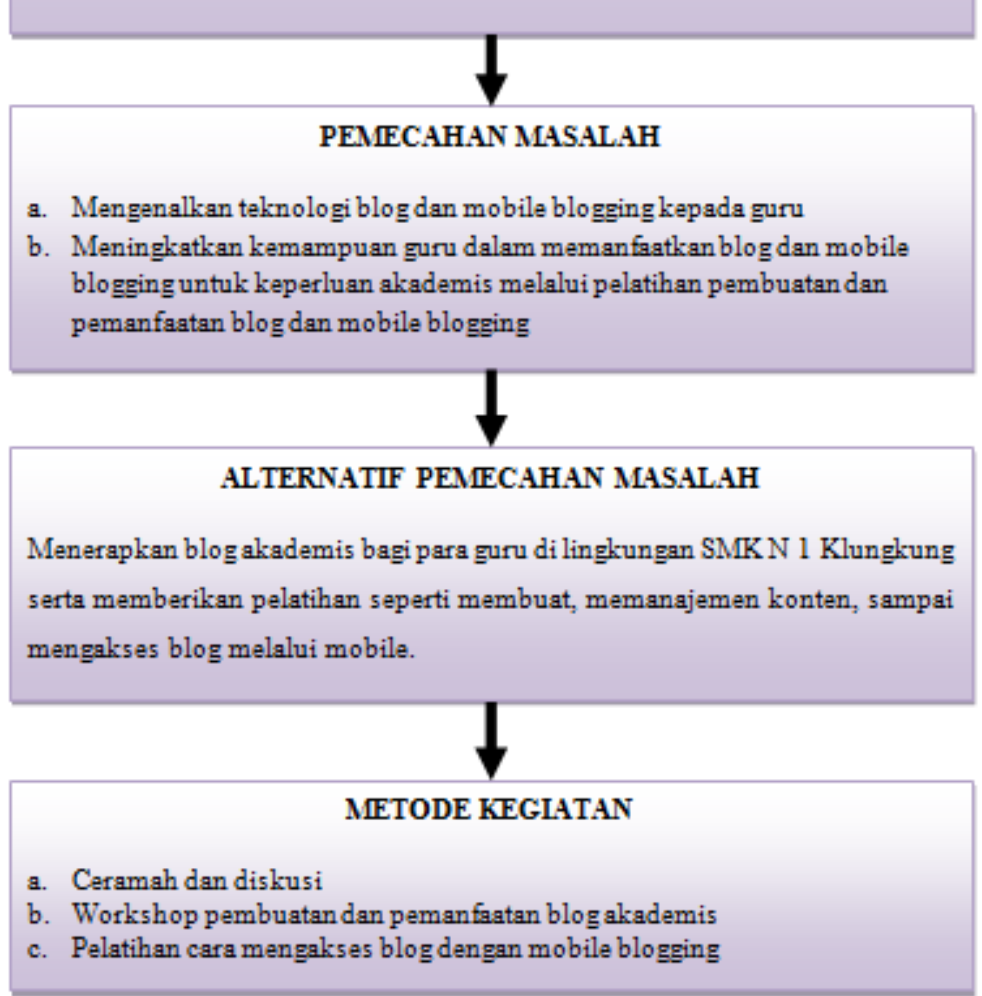

Gambar 5. Kerangka Pemecahan Masalah

Sehingga tak dapat dipungkiri seiring berkembangnya dunia yang sudah modern sekarang ini, maka itu sama pentingnya juga untuk seorang webmaster dan blogger agar blognya harus bisa support atau di optimalkan di perangkat mobile atau mobile friendly, sehingga pembaca bisa mendapatkan tampilan yang juga mendukung versi mobile dengan tampilan yang lebih kecil dan lebih ringan dari situs tersebut tanpa memperlambat waktu loading saat membuka di ponselnya. Beberapa fitur yang sudah disediakan oleh beberapa situs blog yang banyak digunakan terkait dengan mobile blogging misanya saja pada halaman WordPress (lihat Gambar 2), Blogger (lihat Gambar 3). Perbandingan akses masing-masing blog da-pat dilihat pada Gambar 4.

\section{METODE DAN PERANCANGAN SISTEM}

\section{KERANGKA PEMECAHAN MASALAH}

Berangkat dari permasalahan yang dihadapi maka alternatif pemecahan masalah yang akan dilaksanakan dalam kegiatan P2M ini dapat dilihat pada Gambar 5.

\section{METODE KEGIATAN}

Metode dalam kegiatan ini adalah perkenalan dengan teknologi blog dan mobile blogging kepada para guru serta pelatihan terhadap para guru dengan tujuan supaya mereka dapat mengisi konten blog masingmasing sesuai dengan kebutuhannya. Kemudian peserta dapat mengakses blog yang sudah dibuat dengan menggunakan mobile blogging. 


\section{RANCANGAN EVALUASI}

Evaluasi terkait kegiatan ini dilakukan sesuai dengan permasalahan.

- Aspek yang dievaluasi terkait kehadiran, aktivitas peserta, respon dan kemampuan membuat blog.

- Evaluasi terkait pelatihan mencakup kemampuan peserta pelatihan mengisi konten blog sesuai dengan ilmu yang diajarkan masing-masing.

- Evaluasi terkait pengaksesan mencakup kemampuan peserta pelatihan melakukan update dan melihat informasi mobile blogging.

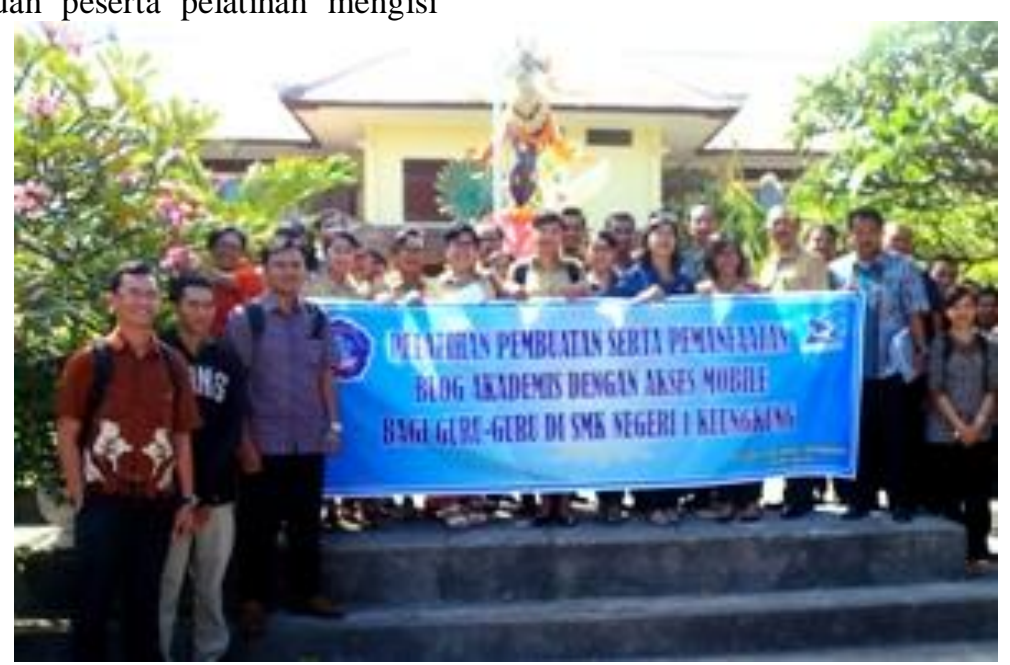

Gambar 6. Dokumentasi Kegiatan

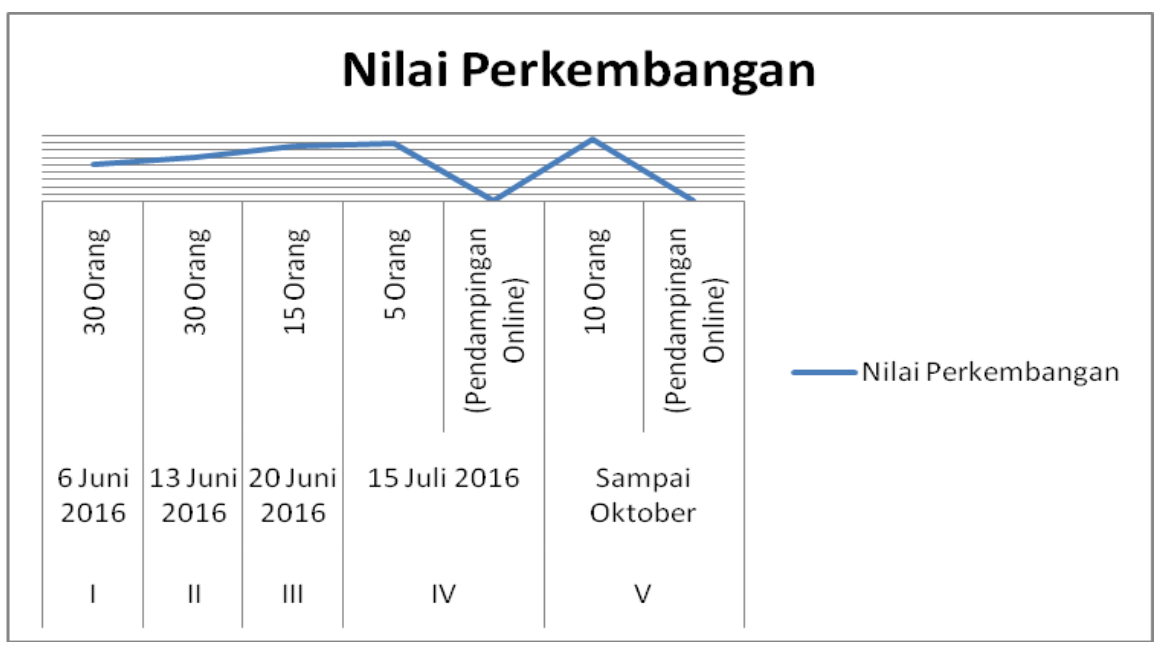

Gambar 7. Grafik Perkembangan Peserta

\section{HASIL DAN PELAKSANAAN KEGIATAN}

Hasil dari kegiatan pengabdian pada masyarakat yang dilaksanakan pada Sekolah SMK N 1 Klungkung mendapat sambutan hangat dari kepala sekolah serta para guru peserta seminar. Adapun jumlah peserta yang semula dipersiapkan 20 Orang, atas permintaan sekolah menjadi 80 Orang. Adapun dokumentasi peserta saat kegiatan dapat dilihat pada Gambar 6.

Dengan jumlah peserta ketua pelaksana pengabdian mengajukan keberatan karena dana yang dianggarkan untuk kegiatan hanya $\mathrm{Rp}$ 11.000.000. Akhirnya pihak sekolah menawarkan solusi, akan bersedia membantu menyediakan konsumsi untuk kegiatan. Adapun pelaksanaan kegiatan dibagi menjadi 5 sesi utama yang dapat dilihat dalam bentuk grafik pada Gambar 7.

\section{SIMPULAN}

Berdarkan observasi kegiatan ngelog yang dilakukan para guru, dapat dikatakan bahwa perkembangan pada saat bulan Juni sampai bulan Oktober sudah nampak ada 
kemajuan. Saat awal para guru sudah tertarik dengan sangat antusias mengikuti pelatihan. Semua guru tanpa dibatasi usia ikut kompak dalam proses pelatihan, sehingga membuat panitia harus bekerja keras untuk melayani masing-masing peserta dengan jumlah yang terbatas. Pada pertengahan Juli, Tim coba untuk mengontak salah seorang guru untuk menanyakan tentang perkembangan yang terjadi setelah melakukan pelatihan. Kemudian berlanjut dengan pendampingan online yang akhirnya, di sela-sela kesibukan guru sebanyak 10 orang sudah berhasil mendaftarkan halaman Blog secara online dan selanjutnya siap untuk digunakan publish materi pelajaran. Adapun hasil yang diperoleh dalam kegiatan ini adalah cukup efektif membuat para guru untuk semakin berminat mengembangkan kemampuannya ngeblog sehingga banyak informasi yang dapat di saring ke siswa maupun orang tua siswa.

\section{DAFTAR PUSTAKA}

[1] Betha, S., 2004, Pemrograman Web dengan PHP, Bandung:Informatika.

[2] Haines, R., 2010. Keep parents in the loop with a class website, http://www.learnnc.org/lp/pages/6639, (Accessible 5 Nov, 2016)

[3] Hasan, Wahid., 2012, Cara Mudah Membuat Blog Versi Mobile (WordPress dan Blogger), http://ngonoo.com/, diakses (29 okt 2015, 1:09).

[4] Lie, Oktavia, 2014, Cara Membuat Blog Support Mobile Friendly, http://www.madamvia.web.id/, diakses (29 okt 2015, 9:58).

[5] Ristianto, E. C., 2015, Pengertian Blog, Fungsi dan Kegunaannya, http://www.ekocandra.zone/, diakses (29 Okt 2015, 1:39).

[6] Siswoyo, Agus., 2011, Mobile Blogging: Kelebihan dan Kekurangan Ngeblog Melalui Handphone.

http://http://agussiswoyo.com/, diakses (29 okt 2015, 9:35).

[7] Sutiyadi, M., 2006, Pengenalan Internet Retrieved 2014, http://ilmukomputer.com/2006/08/20/peng enalan-internet. 